\title{
Dynamics of Entangled Networks in Ultrafast Perforation of Polystyrene Nano-membrane
}

\author{
Wanting Xie, Jae-Hwang Lee* \\ Department of Mechanical and Industrial Engineering, University of Massachusetts, Amherst, \\ Massachusetts 01002, USA. \\ ${ }^{2}$ Department of Physics, University of Massachusetts, Amherst, Massachusetts 01002, USA.
}

*Correspondence to: leejh@umass.edu

KEYWORDS: micro-ballistic testing, high strain rate, impact, molecular weight, polystyrene. 

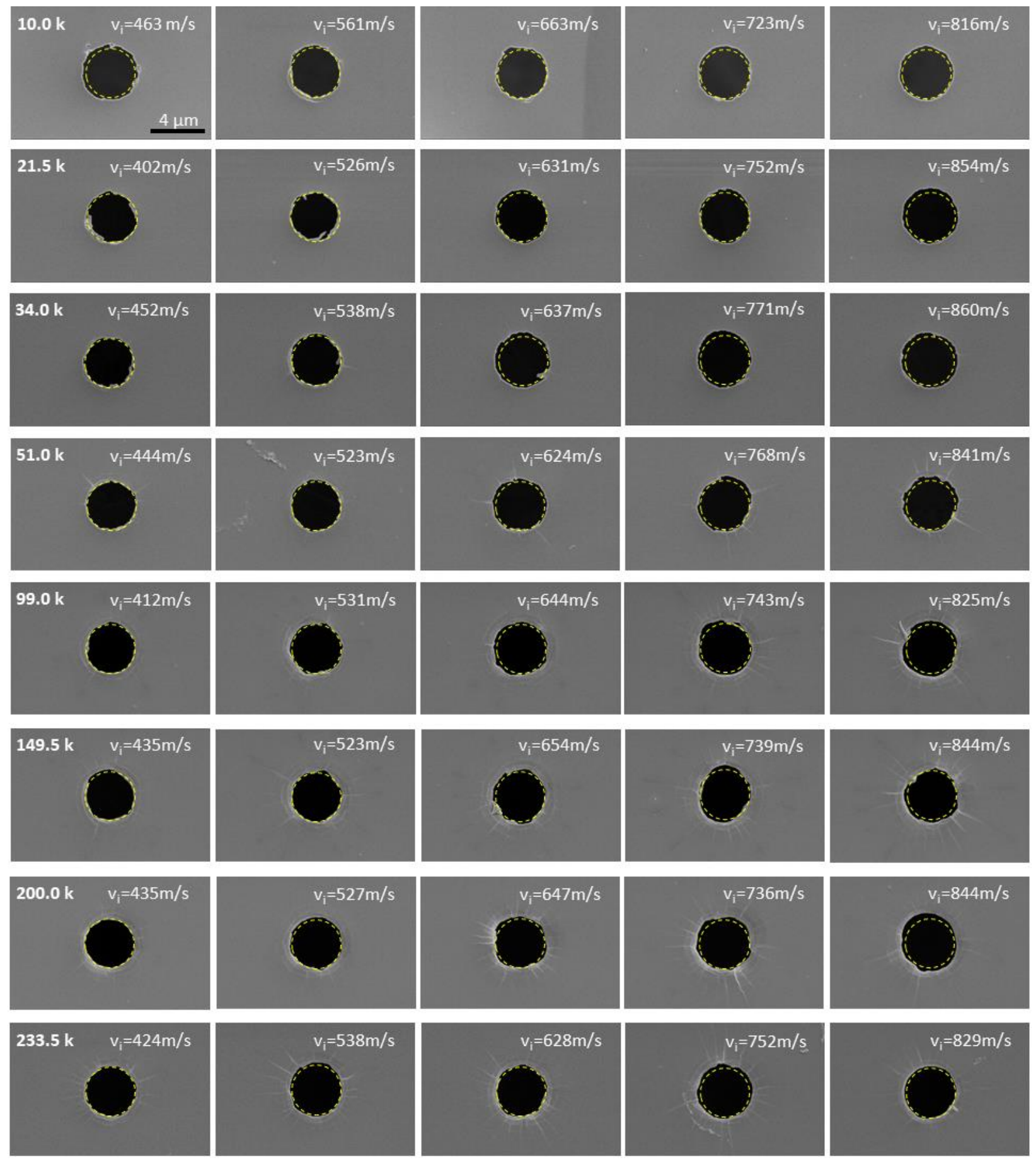

Figure S1. Post-penetration SEM images of different molecular weights at various impact speeds. 